\title{
AC 2012-4594: EXAMINING OUTCOMES DATA FROM AN UNDERGRAD- UATE INTERNSHIP PROGRAM
}

Mr. Bryan E. Dansberry, NASA Johnson Space Center

Bryan Dansberry has been involved in experiential education for nearly 30 years as a co-op student, mentor, professor, and now internship Project Manager. As a member of ASEE, he has served actively in the leadership of the Cooperative and Experiential Education Division. 


\title{
Examining Outcomes Data from an Undergraduate Internship Program
}

\begin{abstract}
In 2008 NASA's Undergraduate Student Research Program (USRP) implemented an end-to-end on-line database system to manage internship processes from application and selection through near-term evaluation and long-term retention outcomes. From 2008 through 2011 this database documented over 10,000 applicants and 1,415 STEM internship experiences.

This paper presents initial findings from the analysis of this database, including information on cognitive and affective learning outcomes, post-graduation retention including career and academic choices, and employer return-on-investment metrics.
\end{abstract}

\section{Introduction}

When viewed from the broadest employer perspective, full-immersion experiential programs such as internships or co-op generate positive outcomes in three general areas:

1. student competencies (learning)

2. useful productivity (task completion)

3. retention (graduation, advanced degrees, employment, career longevity)

Typically, metrics collected for internships focus on participant demographics and retention outcomes in terms of employment specific to the employer sponsoring the program. In STEM fields, where current graduation rates are not expected to keep up with projected needs, increasing the participation of underrepresented groups takes on increased significance beyond social justice implications. Encouraging talented students within these groups to enter STEM fields at a higher rate is a logical means to reduce the predicted gap. Therefore, tracking the numbers of underserved and underrepresented participants is important. However, most internship programs fail to capture learning outcomes making it difficult to determine the impact of the experience. Thus, internship project managers have no immediate data to gauge the effectiveness of their programs in preparing participants for STEM career success and/or increasing their commitment to STEM careers.

Retention data, such as number of alumni successfully completing their degree program, moving on to advanced STEM degrees, and ultimately entering the STEM workforce is the gold standard measure of success for experiential programs. However, retention data requires longitudinal tracking of student alumni to determine graduation rates, career choices, and employment history. While important, capturing this information requires a high level of effort - often exceeding the resources available to experiential program managers in government organizations. Additionally, retention outcomes require years to emerge as students complete their undergraduate degrees, decide whether or not to pursue graduate programs, and finally enter the workforce. Because of this long time-lag between participation in the experiential program and eventual hiring into the workforce, retention data can be a poor tool for program managers looking to implement continuous improvements to their programs in the short term. Moreover, retention data alone often does not carry the weight necessary to defend experiential 
programs from budget cuts in times of fiscal "belt-tightening." When budgets are tight, financial decisions are often made on the basis of immediate impact as opposed to long-term benefits.

In 2008, NASA's Undergraduate Student Research Program (USRP) implemented an end-to-end on-line database system to more efficiently manage internship processes from application and selection through documentation of the experience. Simultaneously, project managers instituted new end-of-internship surveys for both students and mentors designed to better capture immediate outcomes generated in the areas of student learning and productivity. Outcomes in the areas of student learning provide immediate information to experiential program managers in monitoring the rigor and challenge of student experiences, maximizing the quality of the selection process in matching specific students to specific mentors and projects, and in capturing student growth in areas directly related to the ABET a-k criteria. Additionally, data gathered in the area of productivity can be used to estimate the value of the work produced by students to the organization - a metric which can carry significant weight in defending experiential program budgets during difficult economic times.

From 2008 through 2011 this database system has documented over 10,000 qualified applicants and 1,415 STEM internship experiences. Included in this database are 1080 student surveys and 780 mentor surveys. The following sections document findings from the initial analysis of this data set coupled with results of the long-term tracking of project alumni. Additionally, the student productivity data is used to generate a return on investment measure intended to estimate the dollar value of student productivity generated by the USRP internship program. The data presented represents internships at 12 NASA worksites and in spring, summer and fall sessions.

\section{NASA's Undergraduate Student Research Project}

From 2008 - 2011 USRP was NASA's largest agency-wide internship program with an annual budget of over $\$ 3$ million. Over the 4-year time-period, USRP generated 1415 internships with participants representing over 300 colleges and universities as well as all 50 states. In order to be eligible for USRP, students were required to be enrolled full-time in an accredited engineering, physical science, biological science, computer science, or mathematics degree program. USRP was open to U.S. Citizen undergraduate students, sophomore and above, with a minimum 3.0 cumulative GPA on a 4 point scale. On average, over 3,000 qualified students completed applications for USRP internships each year, representing over 900 academic institutions. The 300+ students selected represented over 180 institutions annually.

USRP internships were full-time (40 hrs/wk), stipend-paid, discipline-specific experiences. Student candidates were selected by individual NASA technical mentors based on the required skills and aptitudes necessary for their specific research project or engineering task-load. In order to assure the experience offered matched their interests and career goals, students were provided a short description of the specific work-assignment in their official internship offer. Students also had the opportunity to seek clarification before accepting the internship.

Figure 1 shows the high level of satisfaction in this matching process by USRP mentors over the 4-year span captured in the database. A total of $95 \%$ of the mentors rated the matching of their 
intern to their project to be good to excellent (based on their previous experiences with student interns and co-ops) while less than $2 \%$ found the match to be poor.

Figure 1. Quality of student-mentor matching.

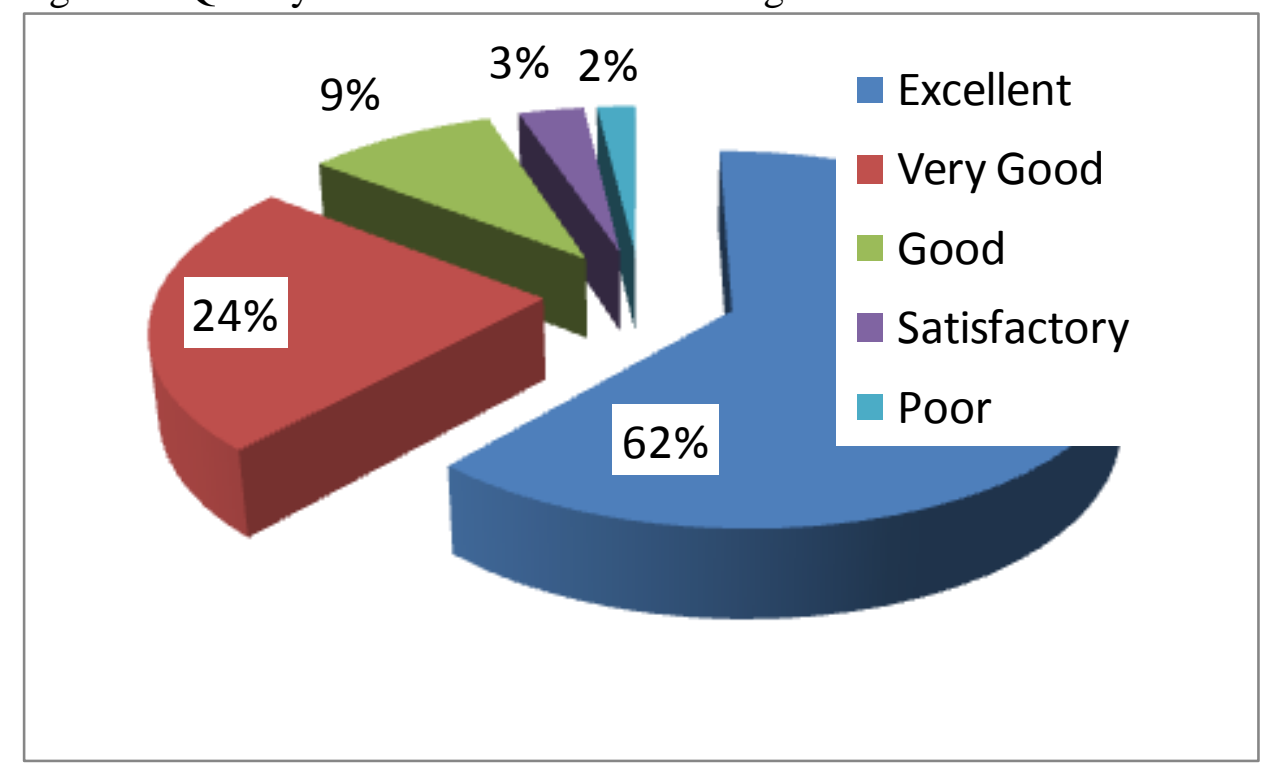

In addition to the experience gained through the work assignments provided by their mentors, USRP students are required to write and submit a technical paper on their core research or engineering activities by the end of their internship. These reports are required to follow AIAA (American Institute of Aeronautics and Astronautics) conference paper guidelines. As of January, 2012 over 120 of these reports had completed NASA export control processes and were published on the USRP website (www.usrp.usra.edu). Additionally, all interns were required to either give an exit technical presentation to upper management of the technical organizations they had been embedded within, or to participate in a poster session attended by personnel across the particular NASA center at which they worked. These requirements provided extensive technical communication experience intended to benefit the students while simultaneously fostering organizational communications within NASA.

\section{The USRP Dataset}

The data presented in this paper represents internships conducted from spring 2008 through fall 2011. During that span there were 1415 USRP internships hosted by 12 NASA work-sites. Each year USRP placed students during 3 internship sessions: spring (457), summer (587), and fall (371). Summer USRP internships were 10 weeks in length, while spring and fall internships were 15 weeks long. The distribution of internships by worksite and session can found in Table 1 .

Of the 1415 internships documented in this dataset, 1080 student exit surveys and 780 mentor surveys were collected. The following sections discuss aspects of the data collected in these surveys.

Table 1. Distribution of internships by session and worksite. 


\begin{tabular}{|c|c|c|c|c|c|c|c|c|c|c|c|c|c|}
\hline & & \multicolumn{12}{|c|}{ NASA Facilities } \\
\hline & Total & Ames & Dryden & Glenn & Goddard & JPL & JSC & $\mathrm{KSC}$ & Langley & Marshall & Stennis & Wallops & $\begin{array}{l}\text { White } \\
\text { Sands }\end{array}$ \\
\hline Spr '08 & 74 & 4 & 1 & 13 & 6 & 9 & 7 & 7 & 9 & 9 & 3 & 4 & 2 \\
\hline Su '08 & 149 & 20 & 3 & 21 & 3 & 23 & 13 & 18 & 12 & 23 & 6 & 5 & 2 \\
\hline Fall '08 & 97 & 10 & 0 & 12 & 8 & 16 & 17 & 8 & 5 & 12 & 3 & 4 & 2 \\
\hline FY'08 Totals & 320 & 34 & 4 & 46 & 17 & 48 & 37 & 33 & 26 & 44 & 12 & 13 & 6 \\
\hline Spr '09 & 106 & 10 & 5 & 13 & 9 & 15 & 18 & 6 & 7 & 11 & 5 & 4 & 3 \\
\hline Su '09 & 144 & 16 & 5 & 21 & 6 & 19 & 13 & 15 & 15 & 20 & 6 & 5 & 3 \\
\hline Fall '09 & 91 & 10 & 4 & 10 & 9 & 16 & 15 & 0 & 6 & 12 & 2 & 4 & 3 \\
\hline FY'09 Totals & 341 & 36 & 14 & 44 & 24 & 50 & 46 & 21 & 28 & 43 & 13 & 13 & 9 \\
\hline Spr'10 & 99 & 12 & 4 & 14 & 8 & 14 & 15 & 6 & 7 & 9 & 3 & 4 & 3 \\
\hline Su'10 & 113 & 9 & 7 & 25 & 8 & 16 & 11 & 7 & 8 & 10 & 6 & 2 & 4 \\
\hline Fall '10 & 94 & 12 & 4 & 18 & 14 & 13 & 10 & 0 & 5 & 10 & 2 & 4 & 2 \\
\hline FY'10 Totals & 306 & 33 & 15 & 57 & 30 & 43 & 36 & 13 & 20 & 29 & 11 & 10 & 9 \\
\hline Spr'11 & 178 & 25 & 7 & 26 & 17 & 26 & 27 & 5 & 12 & 20 & 3 & 6 & 4 \\
\hline Su'11 & 181 & 22 & 7 & 26 & 22 & 25 & 16 & 12 & 15 & 21 & 6 & 4 & 5 \\
\hline Fall '11 & 89 & 11 & 3 & 13 & 11 & 11 & 17 & 0 & 8 & 8 & 1 & 4 & 2 \\
\hline FY '11 Totals & 448 & 58 & 17 & 65 & 50 & 62 & 60 & 17 & 35 & 49 & 10 & 14 & 11 \\
\hline \multicolumn{14}{|l|}{ Spr'12 } \\
\hline \multicolumn{14}{|l|}{ Su'12 } \\
\hline \multicolumn{14}{|l|}{ Fall '12 } \\
\hline \multicolumn{14}{|l|}{ FY '12 Totals } \\
\hline Total & 1415 & 161 & 50 & 212 & 121 & 203 & 179 & 84 & 109 & 165 & 46 & 50 & 35 \\
\hline
\end{tabular}

\section{Student Learning: Cognitive Skills}

Table 2 shows the percentage of USRP interns who indicated in exit surveys that their experience provided them growth opportunities in areas closely aligned to ABET a-k criteria. These are areas deemed critical to success in engineering and technology careers. Overall, this data indicates that USRP internship experiences are appropriately rigorous and challenging, providing student's ample opportunity to grow in many of the areas considered critical in producing a highly qualified pool of future engineers and scientists for the nation's technical workforce.

Table 2. Percentage of USRP interns indicating growth in key skill areas.

\begin{tabular}{ll}
\hline Professional/Tech. Communication & $98 \%$ \\
Conceptual/Analytical Ability & $99 \%$ \\
Learning/Applying Knowledge & $99 \%$ \\
Professional Qualities & $98 \%$ \\
Teamwork & $93 \%$ \\
Leadership & $88 \%$ \\
Technology & $97 \%$ \\
Work Culture & $99 \%$ \\
Organization/Planning & $97 \%$
\end{tabular}

By assigning numerical values to the student responses in these areas, USRP project managers created a numerical score which provided a comparison of the learning benefits of individual internship experiences as they relate to those core abilities defined in the ABET a-k criteria. 
Over time, as multiple students rated their learning opportunities under a single mentor, this score proved useful in identifying exceptional mentors on both the positive and negative ends of the spectrum.

\section{Student Learning: Attitudinal Change}

While skill development is an important outcome in any experiential program, attitudinal change may be the single most important factor in predicting the long-term retention benefits of an internship program. For example, if an experience can be shown to increase a students' professional self-confidence, the chances that student will persevere through graduation and into a stem career are significantly improved. In their exit surveys, USRP interns were asked a series of questions designed to determine how their USRP experience affected their commitment and attitude in regards to their current career path. Table 3 shows the responses of the students to these questions. The percentage given represents the number of interns who expressed agreement with the statement. Considering the fact that about $50 \%$ of USRP interns were seniors, the results shown are another indication of the strong impact hands-on experiential opportunities have on student development.

Table 3. Student responses to affective questions in USRP survey. This experience helped me determine my own strengths and weaknesses: $96 \%$ This experience increased my professional self-confidence: $\quad 98 \%$ This experience increased my academic motivation: $96 \%$ This experience increased my understanding of my chosen profession: $\quad 95 \%$ This experience helped me to clarify my career plans and options: $\quad 97 \%$ This experience helped prepare me to achieve my career goals: $\quad 98 \%$

\section{Student Productivity}

Another outcome of internships which has not often been captured previously is useful technical productivity. This data is captured for USRP in the Mentor survey by asking mentors to compare the useful technical productivity of their student intern compared to a typical fresh-out new hire in their organization. While this opinion can only lead to an approximation of the actual value, results have remained consistent for those sessions in which mentor surveys were collected from more than $50 \%$ of the internships.

Based on 740 mentor surveys, USRP interns produce useful technical work at a rate of $104 \%$ as compared to a fresh-out new hire. As stated above, this value has remained constant (+/- 10\%) over 12 internship sessions. While the first reaction of the reader may be to accuse NASA mentors of being overly generous, it is important to note that the average NASA engineer or scientist spends a significant amount of each day in meetings. These productivity ratings may indicate that a bright student, well matched in interest and ability to a specific project, and highly motivated to prove him-or-herself, with the advantage of having more time and fewer distractions on any given day, can match or exceed the output of early career professionals. 
USRP program managers use this productivity measurement to estimate immediate return on investment to NASA in terms of technical productivity generated by interns. The following equation is used to generate a dollar value:

Productivity $(\$)=$ mentor rating $\mathrm{x}$ ave. starting salary+benefits $\mathrm{x}$ total length of internships

Using this equation, over the 4-year span of this dataset USRP interns generated approximately $\$ 28$ million in useful technical work furthering NASA's technical missions. This represents a positive return on investment of $\$ 2$ for each dollar spent to fund USRP internships.

\section{Retention Outcomes}

In parallel with the data collected through exit surveys, USRP managers have worked diligently to track program alumni and document their graduation rates and career choices. Table 4 shows the results of these data collection activities. Of the 388 USRP alumni successfully tracked, only 8 have exited the STEM pipeline. While this result is considered an outstanding indication that the USRP internship program is maximizing it's impact on student-participants, further study of the database may indicate which of those immediate outcomes measured best predicts these long-term retention gains.

\begin{tabular}{|c|c|c|c|c|c|c|c|c|c|c|c|c|c|c|c|}
\hline & \multicolumn{2}{|c|}{ Cohort } & \multicolumn{2}{|c|}{ Not Graduated Yet } & \multicolumn{3}{|c|}{ Pursuing Advanced Degree } & \multicolumn{6}{|c|}{ Employed } & \multicolumn{2}{|c|}{ Unemployed } \\
\hline & $\begin{array}{c}\text { Total } \\
\text { Cohort }\end{array}$ & $\begin{array}{c}\text { Respond } \\
\text { ents }\end{array}$ & $\begin{array}{c}\text { Still } \\
\text { Pursuing }\end{array}$ & $\begin{array}{c}\text { Not } \\
\text { Pursuing }\end{array}$ & $\begin{array}{c}\text { STEM } \\
\text { Masters }\end{array}$ & $\begin{array}{c}\text { STEM } \\
\text { PhD }\end{array}$ & $\begin{array}{l}\text { Non- } \\
\text { STEM }\end{array}$ & $\begin{array}{l}\text { NASA or } \\
\text { JPL }\end{array}$ & $\begin{array}{l}\text { Aero- } \\
\text { space }\end{array}$ & $\begin{array}{r}\text { Higher Ed } \\
\text { Academi }\end{array}$ & $\begin{array}{l}\text { Educ- } \\
\text { ation }\end{array}$ & $\begin{array}{l}\text { Other } \\
\text { STEM }\end{array}$ & $\begin{array}{l}\text { Non- } \\
\text { STEM } \\
\end{array}$ & $\begin{array}{c}\text { Seeking } \\
\text { Job }\end{array}$ & $\begin{array}{c}\begin{array}{c}\text { Not } \\
\text { Seeking }\end{array} \\
\end{array}$ \\
\hline Total & 747 & 388 & 61 & 0 & 98 & 73 & 0 & 20 & 53 & 6 & 5 & 54 & 2 & 7 & 6 \\
\hline$\%$ & N/A & $51.9 \%$ & $100.0 \%$ & $0.0 \%$ & $57.3 \%$ & $42.7 \%$ & $0.0 \%$ & $14.3 \%$ & $37.9 \%$ & $4.3 \%$ & $3.6 \%$ & $38.6 \%$ & $1.4 \%$ & & \\
\hline \multicolumn{3}{|c|}{ Total in category } & \multicolumn{2}{|c|}{61} & \multicolumn{3}{|c|}{171} & \multicolumn{6}{|c|}{140} & \multicolumn{2}{|c|}{13} \\
\hline \multicolumn{3}{|c|}{ Percentage of Respondents } & \multicolumn{2}{|c|}{$15.7 \%$} & \multicolumn{3}{|c|}{$44.1 \%$} & \multicolumn{6}{|c|}{$36.1 \%$} & \multicolumn{2}{|c|}{$3.4 \%$} \\
\hline \multicolumn{3}{|c|}{ Retention in STEM Pipeline } & \multicolumn{2}{|c|}{$100.0 \%$} & \multicolumn{3}{|c|}{$100.0 \%$} & \multicolumn{6}{|c|}{$98.6 \%$} & \multicolumn{2}{|c|}{$N / A$} \\
\hline
\end{tabular}

The reader may note that while the overall retention within the STEM pipeline is outstanding, the number of students eventually employed by NASA is much lower than you would find in internship or co-op programs in the private sector. This is a normal characteristic of internship programs at government agencies - which tend to be sized based on available funds as opposed to planned hiring needs. In evaluating the success of this program, NASA considers alumni employed in aerospace, academia, and education to be of equal value to those employed by the agency itself.

\section{Summation}

The dataset generated by the USRP internship program over the last four years is substantial and unique. It includes application data for over 10,000 applicants and 1,415 selected interns. The database also contains ??? student exit surveys and 740 mentor surveys, tied to each other and the application data, providing data on learning outcomes, attitudinal changes, and productivity outcomes. Finally, long-term retention data for 388 alumni are included showing the advanceddegree and career choices made after graduation.

Data presented shows that significant opportunities to develop and demonstrate ABET a-k skills and abilities were generated by the internships. Also, students exhibited attitudinal changes indicating the experience both increased their self-confidence and desire to complete their 
academic program and enter the STEM workforce. Finally, significant productivity was generated which benefited NASA at a rate of $\$ 2$ for each $\$ 1$ spent on the interns. While analysis is ongoing, initial findings indicate that there is a lot to be learned from a careful study of the immediate outcomes of an internship program.

\section{Bibliography}

Accreditation Board For Engineering and Technology, [Engineering Accreditation Commission, ABET/EAC] (1997). Engineering Criteria 2000, $3^{\text {rd }}$ Ed., Atlanta, Ga., Accreditation Boardfor Engineering and Technology.

Dansberry, Bryan. Capturing immediate learning outcomes of undergraduate internships: NASA's Undergraduate Student Research Project. Proceedings, ASEE 2009 Annual Conference.

Dansberry, Bryan. Capturing immediate learning outcomes of undergraduate internships. Johnson Space Center Biennial Report, December, 2011. 